Reprinted with permission from Weed Technology. 1997. 11(4):798-803.

Published and copyrighted by: Weed Science Society of America, http://www.wssa.net

\title{
Image analysis of leafy spurge (Euphorbia esula) cover $^{1}$
}

\author{
JENNIFER L. BIRDSALL, PAUL C. QUIMBY, JR., NORMAN E. REES, TONY J. \\ SVEJCAR, and BOK F. SOWELL
}

Botanist, USDA-FS Forestry Sciences Laboratory, Bozeman, MT 59717; Plant Physiologist, Entomologist, USDA-ARS, Sidney, MT 59270; Range Scientist, USDA-ARS Eastern Oregon Agricultural Research Center, Burns, OR 97720, and Assistant Professor, Department of Animal and Range Sciences, Montana State University, Bozeman, MT 59717.

\begin{abstract}
:
We examined whether image analysis could separate leafy spurge from other plant species and objects by comparing image analysis to the ocular method of estimating cover. Image analysis was acceptably precise at low and medium cover levels. Image analysis was as repeatable as the ocular method at all sites and cover levels and acceptably reliable at low and medium cover levels but estimated cover lower by 12 to $22 \%$ than the ocular method at high cover levels. The average error levels of image analysis and the ocular method did not differ. Estimating leafy spurge cover with a $10 \%$ error required only 20 quadrats when image analysis was used, while twice as many quadrats were needed when cover was measured ocularly. Image analysis was recommended as a measurement tool because quantification was efficient, the equipment is inexpensive, and the color prints provide a permanent photo record of the study.
\end{abstract}

\section{Nomenclature:}

Leafy spurge, Euphorbia esula L. $\#^{2}$ EPHES.

\section{Additional index words:}

Plant measurements, plant sampling.

\footnotetext{
${ }^{1}$ Received for publication October 29. 1996, and in revised form August 27, 1997.

${ }^{2}$ Letters following this symbol are a WSSA-approved computer code from Composite List of Weeds, Revised 1989. Available from WSSA, 810 East 10th Street, Lawrence, KS 66044-8897.
} 


\section{Introduction}

In biological control of weed programs, researchers and land managers have monitored the effects of introduced weed-attacking agents on vegetation with several measures, each with inherent strengths and weaknesses. Currently, researchers often assess the effects of biological control agents by ocularly estimating plant canopy cover. While ocular estimates of plant canopy cover can be used to describe trends in vegetation (Brown 1954), researchers have long recognized that the accuracy and precision of ocular cover estimates depend on the subjectivity of the estimator (Fisser and Van Dyne 1966, Smith 1944). Significant bias can occur between different estimators and between the same estimator during a single sampling period and does not seem to decrease with estimator experience (Bonham 1989; Hutchings and Pase 1963; Schultz et al. 1961). The use of computer-aided image processing procedures may enable researchers to monitor changes in plant canopy cover with less bias.

Image analysis is an electronic technique in which analog images are converted to digital format to permit computer analysis. In black and white image analysis specific picture elements (pixels) of the digital image can be isolated and classified using a gridscanning pattern. Each pixel is assigned a data quantization level, termed a gray level. An operator specifies a subset of gray levels that correspond to the objects targeted for classification, and the computer can then quantify the proportional area occupied by the pixels within the subset (Gerten and Wiese 1987). The fundamental purpose of image analysis is to digitize, store, and process an image to extract information about a specific response (Stutte 1990). While the technological requirements for image analysis are generic and relatively inexpensive, image analysis must also be rapid to have practical value. The additional laboratory time required to obtain the image analysis data from color prints has been examined in several studies. After developing a routine, McMillan and Schwartz (1993) could obtain and analyze images of leaves in 20 to $30 \mathrm{~s}$. Thomas et al. (1988) found that it took $52 \mathrm{~s}$ on average to visually inspect a slide and $104 \mathrm{~s}$ for image analysis. The time required to visually inspect a slide increased as percent cover increased but remained relatively constant for image analysis. Thomas et al. (1988) also noted that visually inspected data are generally recorded on paper. Additional processing time would be needed to enter the visual data onto a computer.

Studies comparing image analysis to more conventional methods of measuring plant cover have indicated image analysis may be more accurate and efficient than visual methods. Thomas et al. (1988) used image analysis to measure percent cover of rapeseed (Brassica napus L.) from color slides. The researchers determined that image analysis estimated rapeseed canopy more accurately than the visual method when compared to cover measures obtained using a leaf area meter. Molloy and Moran (1991), using a random process model to examine error levels for image analysis and the ocular grid method of measuring crop residue cover from prints, found the error level of the ocular method to be 27 times higher on average than error for the image analysis method. However, studies comparing the repeatability of image analysis have produced mixed results. Stone et al. (1988) found image analysis as repeatable as the ocular grid method at estimating cover

of carrot (Daucus carota L.), lettuce (Lactuca sativa L.), and onion (Allium cepa L.) from false color infrared images, while Nutter et al. (1993) found image analysis to be less re- 
peatable than the visual method of estimating percent disease severity on bentgrass (Agrostis palustris Huds.).

We wanted to determine whether we could substitute image analysis for ocular estimation of the effects of biological control agents on leafy spurge canopy cover. Since image analysis separates objects based on reflectance coefficients and many plant species including leafy spurge have characteristic reflectance signatures (Everitt et al. 1995; Knipling 1970), we predicted that we could use image analysis to differentiate leafy spurge from other plant species and background objects with at least the same level of precision as the ocular method. To test this, we compared estimates of leafy spurge cover obtained using image analysis to ocular estimates made by observers with varied levels of experience. Specific objectives were to: (1) test the repeatability of image analysis estimates and ocular estimates; (2) examine the similarity between image analysis estimates and ocular estimates; and (3) determine error levels and sample sizes needed to obtain statistically significant estimates of leafy spurge cover based on the image analysis and ocular methods.

\section{Materials and methods}

Study Areas. Study areas were in Fergus and Valley Counties, MT, and Custer County, ID. Leafy spurge was dominant at all three sites and was predominantly in anthesis when data were collected. The Fergus County site was in the unglaciated plains and had a dry subhumid climate with an average annual precipitation of 37 to $48 \mathrm{~cm}$. Major grass species included: western wheatgrass (Agropyron smithii Rydb.); downy brome (Bromus tectorum L.); Idaho fescue (Festuca idahoensis Elmer); timothy (Phleum pratense L.): Kentucky bluegrass (Poa pratensis L.); and needle-and-thread (Stipa comata Trin. \& Rupr.). Major forb species included: licorice [Glycyrrhiza lepidota (Nutt.) Pursh]; black medic (Medicago lupulina L.); alfalfa (Medicago sativa L.); phlox (Phlox L. sp.); slimflower scurfpea (Psoralea tenuiflora Pursh); clubmoss (Selaginella densa Rydb.); and round-leaved thermopsis (Thermopsis rhombifolia Nutt. ex. Richards). Shrubs were minor at the Fergus County site. The Valley County site was in the glaciated plains with a semiarid climate and average annual precipitation of 25 to $35 \mathrm{~cm}$. Major grass species included: crested wheatgrass [Agropyron cristatum (L.) Gaertn.]; western wheatgrass; and smooth brome (Bromus inermis Leyss.). Clubmoss was the only major forb, although numerous minor forb species were present. Major shrub species included: silver sagebrush (Artemisia cana Pursh); fringed sagebrush (Artemisia frigida Willd.): and common snowberry [Symphoricarpos albus (L.) S. F. Blake]. The Custer County site was in the northern cold desert and had a semiarid climate with an average annual precipitation of 20 to $25 \mathrm{~cm}$. Major grass species included: bluebunch wheatgrass [Agropyron spicatum (Pursh) Scribn. \& Smith]; slender wheatgrass [Elymus trachycaulus (Link) Gould ex. Shinners]; downy brome; Sandberg bluegrass (Poa secunda Presl.); and needle-and-thread. Forb species were numerous but minor at the Custer County site. Major shrub species included: black sagebrush (Artemisia nova A. Nels.); big sagebrush (Artemisia tridentata Nutt.); threetip sagebrush (Artemisia tripartita Rydb.); and gray rabbitbrush [Chrysothamnus nauseosus (Pallas) Britt.].

Page 3 of 10 
Plot Design. Six macroplots were established at each site (18 macroplots total). Macroplots were circular with 44-m diam and minimum distances of $0.8 \mathrm{~km}$ between plots. Transects radiated from the center of each macroplot in the four cardinal directions. Ten sampling loci were marked with wooden stakes along each transect. The sampling loci began $8 \mathrm{~m}$ from the center point and continued every $4 \mathrm{~m}$ for 10 stakes, resulting in 40 sampling loci per plot (720 total for all macroplots).

Ocular Cover Estimates. In the summers of 1993 and 1994, one observer (Observer 3) ocularly estimated percent leafy spurge cover in the field at the 720 sampling loci $\left(1,440\right.$ total for both years). The observer estimated leafy spurge cover within $0.1-\mathrm{m}^{2}$ Daubenmire frames with inside dimensions of 20 by $50 \mathrm{~cm}$ (Daubenmire 1959) placed at each sampling locus. The Daubenmire frames were mounted on $30-\mathrm{cm}$ legs for ease of placement in tall vegetation. Two additional observers (Observers 1 and 2) estimated leafy spurge cover from 9- by 13-cm color prints of photographs taken of the Daubenmire frames with a $35-\mathrm{mm}$ single lens reflex camera equipped with a $35-$ to $70-\mathrm{mm}$ lens. The camera was mounted $1 \mathrm{~m}$ above ground level, and the 1,440 photographs were taken using Kodak Gold $200^{3,4}$ color print film with f-stop adjusted for natural light conditions. In 1993, the color photographs were taken up to 2 weeks after the observer estimated leafy spurge cover in the field. Since both the field ocular estimates and the color photographs were taken late in the season after leafy spurge had completed most of its growth, change in leafy spurge cover was expected to be minimal. In 1994, the color photographs and field ocular estimates were taken concurrently. All three observers estimated nonoverlapping leafy spurge cover to the nearest $5 \%$. Although all three observers had undergraduate degrees in plant science, they differed in their levels of training and experience. Observer 1 had formal training and five summers of experience ocularly estimating leafy spurge cover in field studies. Observer 2, while familiar with the concept of plant canopy cover, had no prior training or experience in making ocular estimates. Observer 3 had been trained by Observer 1 to ocularly estimate leafy spurge cover and had a previous summer of experience ocularly estimating leafy spurge cover in the field.

Image Analysis Cover Estimates. Leafy spurge cover was also estimated from the 1,440 color prints using black and white image analysis. Image analysis was conducted on a Compudyne ${ }^{3,5} 486$ personal computer equipped with a PCVISIONplus ${ }^{\mathrm{TM}^{3,6}}$ Frame Grabber video-digitizing board and $\mathrm{Java}^{\mathrm{TM}}{ }^{3,7}$ image analysis software. The original color prints were individually transferred to the system and digitized using a video camera and the video-digitizing board and were displayed on a separate video monitor. The digitized images were 512 by 480 pixels in size. Each pixel corresponded to a particular (x, y) coordinate of the image and was automatically assigned a brightness or gray level in the range of 0 to 255 (eight bits). Only the pixels within the Daubenmire frame were selected for image analysis. The selected pixels were segmented using a threshold of gray values.

\footnotetext{
${ }^{3}$ Mention of trade names does not indicate endorsement by USDA or Montana State University.

${ }^{4}$ Eastman Kodak Co., Rochester, NY 14650.

${ }^{5}$ Compudyne Corp., 120 Union Street, Willimantic, CT 06226.

${ }^{6}$ Imaging Technology Inc., 55 Middlesex Turnpike, Bedford, MA 01730

${ }^{7}$ Jandel Scientific. 1993. Java ${ }^{\mathrm{TM}}$ Image Analysis Software. Jandel Scientific, San Rafael, CA 94901.
} 
An operator (Observer 2) selected the gray value range that corresponded to leafy spurge in the image. The image was then transformed into a binary format where all pixels in the observer-defined threshold were white and all pixels outside the threshold were black. The binary image was compared with the original print and, if the images were not similar, the operator selected a different threshold until the conditions of the original print were achieved. The computer then calculated leafy spurge cover by determining the percentage of white pixels.

Precision. Precision was defined as the relative measure of the repeatability and reliability of the estimates. To compare the repeatability of the ocular and image analysis cover estimates, we selected 10 of the 1993 color prints with cover values ranging from 0 to $100 \%$. Four observers ocularly estimated leafy spurge cover 10 times for each of the 10 prints (once per day for 10 days). Observers 1, 2, and 3 were described above. Observer 4 did not have a degree in plant science but had been trained by Observer 1 to ocularly estimate leafy spurge cover and had two summers of field experience. Leafy spurge cover was also estimated 10 times for each print using image analysis. Repeatability was compared using the mean standard deviation of the 10 estimates for each of the 10 prints overall. Repeatability was further tested by comparing the mean standard deviations at low, medium, and high cover levels to determine if image analysis was more or less repeatable than the ocular method at different levels of cover. The image analysis and ocular cover estimates for a color print were divided into cover level groups depending on the mean of the ocular cover estimates made by the four observers. If the mean, of the ocular cover estimates was $<30 \%$, the image analysis and ocular cover estimates from this color print were placed in the low cover group. If the mean of the ocular cover estimates was in the range of $30 \%$ to less than $70 \%$, the estimates from this color print were placed, in the medium cover group. Similarly, if the mean of the ocular cover estimates was $70 \%$ or greater, the estimates were placed in the high cover group. Because the standard deviations were normally distributed (all $\mathrm{P}>0.11$ ) according to the Shapiro-Wilk test (SAS 1987) and the variances were homogeneous $(\mathrm{P}>0.05)$ according to the Bartlett test (Neter and Wasserman 1974), the data were analyzed using analysis of variance procedures (SAS 1987). The mean variances and Tukey groupings are reported for the four estimators and image analysis overall and at low, medium, and high cover levels.

Reliability was defined as the level of agreement between the image analysis and ocular cover estimates. To test reliability, the 1993 and 1994 image analysis and ocular cover estimates were compared using measures of correlation and Kruskal-Wallis tests (SAS 1987). Kruskal-Wallis tests were used because the data were not normally distributed, did not have homogeneous variances, and were not improved by arcsine transformation. Correlation coefficients are reported for the measures of correlation. For the Kruskal-Wallis tests, mean cover values and nonparametric groupings are reported. The groupings were calculated using a nonparametric multiple comparisons equation (Daniel 1990). Results are reported by site by year. Reliability was further tested by examining the agreement of the image analysis, and ocular estimates at low, medium, and high cover levels to determine if image analysis produced estimates similar to those of the ocular observers at different levels of cover. The image analysis and ocular cover estimates for a single sample locus were divided into cover level groups depending on the mean of the ocular cover estimates made by the three observers. The low, medium, and high cover groups were the same as those used to test repeatability as previously described. The data within each

Page 5 of 10 
cover level group were compared using a Kruskal-Wallis test (SAS 1987). Mean cover values and nonparametric groupings (Daniel 1990) are reported.

Error Level and Sample Size. Error levels of the three ocular estimates and the image analysis estimates were determined for each of the 18 plots by year using the equation: $E=s /(\bar{x} \sqrt{n})$ where $E=$ error level, $s=$ standard error of the mean, $\bar{x}=$ sample mean, and $n=$ number of quadrats. In this study, the number of quadrats was 40 . The number of quadrats per plot required to estimate leafy spurge cover with a $10 \%$ error level at a 95\% confidence level was calculated using the equation: $n=\left(\mathrm{t}^{2} \mathrm{~s}^{2}\right) / \mathrm{E}^{2}$ where $n=$ number of quadrats, $\mathrm{t}=2.022$ (the two-tailed Student's $t$-value for 39 degrees of freedom), $s=$ standard error of the mean, and $E=0.10$ error level (Molloy and Moran 1991; Pieper 1978). High, low, and average error levels and sample sizes are reported along with the Tukey groupings.

\section{Results and discussion}

Precision. The comparison of the mean standard deviations from the image analysis method and the ocular method of estimating cover 10 times from 10 color prints indicates that image analysis is as repeatable as the ocular method at estimating leafy spurge cover overall and at low, medium, and high cover levels. There were no statistical differences in mean standard deviations among image analysis and the four ocular estimators (all $\mathrm{P}>$ $0.05)$.

Table 1. Pearson correlation coefficients (all P-values < 0.01) between the 1993 and 1994 image analysis and ocular leafy spurge cover estimates made by three observers at the Fergus County, Custer County, and Valley County sites.

\begin{tabular}{|c|c|c|c|c|c|}
\hline \multirow[b]{2}{*}{ Year } & \multirow[b]{2}{*}{ Method } & \multirow[b]{2}{*}{ Site } & \multicolumn{3}{|c|}{ Observer } \\
\hline & & & 1 & 2 & 3 \\
\hline \multirow[t]{9}{*}{1993} & Observer 2 & Fergus & 0.85 & & \\
\hline & & Custer & 0.96 & & \\
\hline & & Valley & 0.91 & & \\
\hline & Observer 3 & Fergus & 0.36 & 0.29 & \\
\hline & & Custer & 0.82 & 0.80 & \\
\hline & & Valley & 0.79 & 0.75 & \\
\hline & Image analysis & Fergus & 0.70 & 0.30 & \\
\hline & & Custer & 0.90 & 0.90 & 0.73 \\
\hline & & Valley & 0.74 & 0.68 & 0.66 \\
\hline \multirow[t]{9}{*}{1994} & Observer 2 & Fergus & 0.85 & & \\
\hline & & Custer & 0.93 & & \\
\hline & & Valley & 0.92 & & \\
\hline & Observer 3 & Fergus & 0.82 & 0.85 & \\
\hline & & Custer & 0.91 & 0.93 & \\
\hline & & Valley & 0.91 & 0.94 & \\
\hline & Image analysis & Fergus & 0.78 & 0.71 & 0.63 \\
\hline & & Custer & 0.93 & 0.90 & 0.89 \\
\hline & & Valley & 0.92 & 0.85 & 0.86 \\
\hline
\end{tabular}


Measures of correlation conducted for each site each year provide information on the reliability of image analysis (Table 1). The correlation coefficients between the image analysis and the ocular cover estimates were above 0.62 except in 1993 at Fergus County $(\mathrm{r}=0.30)$. Observers 1 and 2 also had low correlation with Observer 3 at Fergus County $(\mathrm{r}=0.36$ and 0.29$)$, which was attributed to the time difference between the estimates made by Observer 3 and the estimates made using image analysis and by the other observers. The Fergus County estimates presumably would have been influenced most by the time difference because of the larger size and quantity of leafy spurge in the Fergus County plots.

Table 2. Mean cover values and nonparametric groupings from the 1993 and 1994 image analysis and ocular cover estimates made by three observers at the three sites.

\begin{tabular}{|c|c|c|c|c|c|c|}
\hline Year & Site & Method & $\begin{array}{c}\text { Mean cover } \\
\%\end{array}$ & Std. error & Grouping & P-value \\
\hline \multirow[t]{12}{*}{1993} & \multirow[t]{4}{*}{ Fergus } & Observer 3 & 46 & 1.1 & $\mathrm{~A}$ & \multirow[t]{4}{*}{0.01} \\
\hline & & Image analysis & 42 & 1.1 & A & \\
\hline & & Observer 1 & 42 & 1.5 & A & \\
\hline & & Observer 2 & 35 & 1.1 & B & \\
\hline & \multirow[t]{4}{*}{ Custer } & Observer 3 & 31 & 1.9 & $\mathrm{AB}$ & \multirow[t]{4}{*}{0.01} \\
\hline & & Image analysis & 31 & 1.4 & $\mathrm{~A}$ & \\
\hline & & Observer 1 & 30 & 1.9 & $\mathrm{AB}$ & \\
\hline & & Observer 2 & 27 & 1.8 & $\mathrm{~B}$ & \\
\hline & \multirow[t]{4}{*}{ Valley } & Observer 3 & 34 & 1.6 & A & \multirow[t]{4}{*}{0.06} \\
\hline & & Image analysis & 32 & 1.8 & A & \\
\hline & & Observer 1 & 32 & 1.1 & A & \\
\hline & & Observer 2 & 29 & 1.4 & A & \\
\hline \multirow[t]{12}{*}{1994} & \multirow[t]{4}{*}{ Fergus } & Observer 1 & 56 & 1.6 & A & \multirow[t]{4}{*}{0.01} \\
\hline & & Image analysis & 50 & 1.2 & B & \\
\hline & & Observer 2 & 46 & 1.3 & B & \\
\hline & & Observer 3 & 45 & 1.1 & B & \\
\hline & \multirow[t]{4}{*}{ Custer } & Observer 3 & 17 & 1.0 & A & \multirow[t]{4}{*}{0.01} \\
\hline & & Observer 2 & 15 & 0.9 & A & \\
\hline & & Observer 1 & 14 & 1.1 & $\mathrm{AB}$ & \\
\hline & & Image analysis & 11 & 0.9 & $\mathrm{~B}$ & \\
\hline & \multirow[t]{4}{*}{ Valley } & Observer 1 & 29 & 1.5 & $\mathrm{AB}$ & \multirow[t]{4}{*}{0.01} \\
\hline & & Observer 2 & 27 & 1.2 & A & \\
\hline & & Observer 3 & 26 & 1.1 & $\mathrm{AB}$ & \\
\hline & & Image analysis & 23 & 1.2 & $\mathrm{~B}$ & \\
\hline
\end{tabular}

Results from the Kruskal-Wallis tests between the image analysis and ocular cover estimates at the three sites each year provide further information on the agreement between image analysis and the ocular method (Table 2). In 1993, the image analysis estimates differed from the ocular estimates of Observer 2 at the Fergus County $(P=0.01)$ and Custer County $(\mathrm{P}=0.01)$ sites. However, examination of the mean cover values 
shows that, overall, image analysis was within $7 \%$ of Observer 2 at Fergus County and within $3.5 \%$ of Observer 2 at Custer County. In addition, the means of the image analysis estimates at all three sites are between those of the observers, indicating that the observers often differ more from each other than they do from image analysis. In 1994, the image analysis estimates differed from the ocular estimates of Observer 1 at Fergus County $(\mathrm{P}=0.01)$, from those of Observers 2 and 3 at Custer County $(\mathrm{P}=0.01)$, and from those of Observer 2 at Valley County $(\mathrm{P}=0.01)$. Image analysis differed by less than $7 \%$ in all cases. Mean cover values determined from the image analysis estimates were lower than those determined from the three observers' ocular estimates at Custer $(\mathrm{P}=0.01)$ and Valley County $(P=0.01)$. Again, the differences were small, with the means of analysis differing by less than $6 \%$. Thus, while image analysis did differ statistically from the ocular method in some cases, the mean cover values determined from the image analysis estimates were always within $7 \%$ of the mean cover values determined from any of the three observers' ocular estimates. Since we do not believe a 7\% difference in leafy spurge cover is excessive for a field study like ours, we deemed image analysis to be acceptably reliable compared to the ocular method. When cover classes are used, estimates that differ by up to $25 \%$ can fall within the same class (Daubenmire 1959).

The reliability of the image analysis and ocular estimates was further tested by comparing the image analysis and ocular estimates at low, medium, and high cover levels (Table 3). At low cover levels, image analysis estimated leafy spurge similarly to Observers 2 and 3 . Observer 1 estimated leafy spurge cover to be lower $(P=0.01)$. However, the mean cover values were all within $5 \%$, which we deemed acceptable for our study. At medium cover levels, image analysis and Observer 3 estimated cover similarly. The image analysis estimates tended to be lower than those of Observer 1 and higher than those of Observer $2(\mathrm{P}=0.01)$. However, the image analysis mean cover value was within $7 \%$ of the mean cover values determined from all three observers' estimates, which we again deemed acceptable. The observers tended to differ more from each other than from image analysis. At high cover levels, the image analysis estimates differed from those of all three observers $(\mathrm{P}=0.01)$. In all cases, image analysis estimated leafy spurge cover to be lower than did the observers, with differences ranging from 12 to $22 \%$. Image analysis may estimate cover to be lower at high cover values compared to the ocular method, because image analysis may better account for foliar openings than the observers. The observers might see cover more as the gross crown spread without accounting for any foliar openings (Daubenmire 1959; Kinsinger et al. 1960).

Error Level and Sample Size. The mean error levels for the image analysis estimates and the ocular estimates made by the three observers when 40 estimates were made per plot ranged from 10 to $12 \%$ and did not differ statistically $(\mathrm{P}=0.36)$. Image analysis resulted in the highest error level found in a plot, $25 \%$. The highest error levels in a plot for the three observers ranged from 18 to $22 \%$. Image analysis also resulted in the lowest error level in a plot, $3 \%$. The lowest error levels in a plot for the three observers were all $5 \%$. When the numbers of quadrats required per plot to estimate leafy spurge cover with a $10 \%$ error at a $95 \%$ confidence level were calculated, differences did exist between image analysis and the ocular method (Table 4). Image analysis required an average sample size of 10 quadrats. This was fewer $(\mathrm{P}=0.01)$ than the 17 quadrats required by Observer 1 and the 15 quadrats required by Observer 3 to achieve the same error, but not different from Observer 2's average of 13 quadrats. Image analysis and Observer 1 tied for the

Page 8 of 10 
lowest number of quadrats needed to achieve a $10 \%$ error level in a plot. Image analysis never needed more than 19 quadrats per plot, while Observers 1, 2, and 3 required 35, 32, and 38 quadrats, respectively.

Table 3. Mean cover values and nonparametric groupings of image analysis and ocular leafy spurge cover estimates made by three observers at low, medium, and high cover levels.

\begin{tabular}{llcccc}
\hline Cover level & Method & Mean cover & Std. error & Grouping & P-value \\
\hline \multirow{4}{*}{ Low } & & $\%$ & & & \\
& Observer 3 & 15 & 0.4 & $\mathrm{~A}$ & 0.01 \\
& Image analysis & 15 & 0.5 & $\mathrm{~A}$ & \\
& Observer 2 & 13 & 0.3 & $\mathrm{~A}$ & \\
& Observer 1 & 11 & 0.4 & $\mathrm{~B}$ & \\
\multirow{4}{*}{ Medium } & Observer 1 & 52 & 0.7 & $\mathrm{~A}$ & 0.01 \\
& Observer 3 & 47 & 0.6 & $\mathrm{~B}$ & \\
& Image analysis & 45 & 0.6 & $\mathrm{~B}$ & \\
\multirow{4}{*}{ High } & Observer 2 & 42 & 0.6 & $\mathrm{C}$ & \\
& Observer 1 & 85 & 0.8 & $\mathrm{~A}$ & 0.01 \\
& Observer 2 & 77 & 1.0 & $\mathrm{~B}$ & \\
& Observer 3 & 75 & 1.2 & $\mathrm{~B}$ & \\
& Image analysis & 63 & 1.5 & $\mathrm{C}$ & \\
\hline
\end{tabular}

Image analysis appears to be a useful tool to determine the effects of biological agents on leafy spurge cover. Although most of the leafy spurge was in anthesis when we collected our data, we noted that image analysis did appear able to separate leafy spurge from other plant species and background objects even when flowers were not present. Since image analysis separates objects based on reflectance, image analysis could be useful not only to measure the effects of biological control agents on leafy spurge, but in any study where stress results in reduced total leaf area of a plant species or community with a characteristic reflectance signature.

Table 4. Highest, lowest, and average sample sizes needed to estimate leafy spurge cover within a $10 \%$ error at a $95 \%$ confidence level based on the 1993 and 1994 image analysis and ocular leafy spurge cover estimates made by the three observers at the 18 plots.

\begin{tabular}{|c|c|c|c|c|c|}
\hline \multirow[b]{2}{*}{ Method } & \multicolumn{3}{|c|}{ Sample size } & \multirow[b]{2}{*}{ Tukey } & \multirow[b]{2}{*}{ P-value } \\
\hline & High & Low & Average & & \\
\hline Observer 1 & 35 & 2 & 17 & $\mathrm{~A}$ & 0.01 \\
\hline Observer 2 & 32 & 4 & 13 & $\mathrm{AB}$ & \\
\hline Observer 3 & 38 & 4 & 15 & A & \\
\hline Image analysis & 19 & 2 & 10 & $\mathrm{~B}$ & \\
\hline
\end{tabular}




\section{Literature cited}

Bonham, C, D. 1989, Measurements for Terrestrial Vegetation. New York: J. Wiley. 338 p.

Brown, D. 1954. Methods of Surveying and Measuring Vegetation. Commonwealth Agricultural Bureau Pastures and Field Crops Bull. 42. Reading, England: Bradley and Sons. 223 p.

Daniel, W. W. 1990. Applied Nonparametric Statistics. 2nd ed. Boston, MA: PWS-Kent Publishing. 635 p.

Daubenmire, R. 1959. A canopy-coverage method of vegetational analysis. Northwest Sci. 33:43-64.

Everitt, J. H., G. L. Anderson, D. E. Escobar, M. R. Davis, N. R. Spencer, and R. J. Andrascik. 1995. Use of remote sensing for detecting and mapping leafy spurge (Euphorbia esula). Weed Technol. 9:599-609.

Fisser, H. G. and G. M. Van Dyne. 1966. Influence of number and spacing of points on accuracy and precision of basal cover estimates. J. Range Manage. 19:205-211.

Gerten, D. M. and M. V. Wiese. 1987. Microcomputer-assisted video image analysis of lodging in winter wheat. Photogrammetric Eng. Remote Sens. 53:83-88.

Hutchings, S. S. and C. P. Pase. 1963. Measurement of plant cover-basal, crown, leaf area. In J. P. Blaisdell and K. W. Parker, eds. Range Research Methods. Forestry Service Miscellaneous Publ. 940. Washington. DC: U.S. Department of Agriculture. pp. 22-30.

Kinsinger, F. E., R. E. Eckert, and P. O. Currie. 1960. A comparison of the line interception variable plot and loop methods as used to measure shrub crown cover. J. Range Manage. 13:17-21.

Knipling, E. B. 1970. Physical and physiological basis for the reflectance of visible and near-infrared radiation from vegetation. Remote Sens. Environ. 1: 155-159.

McMillan, M. S. and H. F. Schwartz. 1993. Use of image analysis to quantify bean leaf damage. Annu. Rep. Bean Improv. Coop. 36: 168-169.

Molloy, J. M. and C. J. Moran. 1991. Compiling a field manual from overhead photographs for estimating crop residue cover. Soil Use Manage. 7:177-183.

Neter, J. and W. Wasserman. 1974. Applied Linear Statistical Models. Homewood. IL: R. D. Irwin. 842 p.

Nutter, F. W. Jr., M. L. Gleason, J. H. Jenco, and N. C. Christians. 1993. Assessing the accuracy, intra-rater repeatability, and inter-rater reliability of disease assessment systems. Phytopathology 83:806-812.

Pieper, R. D. 1978. Measurement Techniques for Herbaceous and Shrubby Vegetation. Department of Animal and Range Science. Las Cruces. NM: New Mexico State University. 148 p.

[SAS] Statistical Analysis Systems. 1987. Statistical Analysis System. Release 6.04. Cary, NC: Statistical Analysis Systems Institute.

Schultz, A. M., R. D. Gibbons, and L. DeBano. 1961. Artificial populations for teaching and testing range techniques. J. Range Manage. 14:236-242.

Smith, A. D. 1944. A study of the reliability of range vegetation estimates. Ecology 25:441-448.

Stone, D. A., B. Lancashire, R. A. Sutherland, K. B. Niendorf, and R. B. Sampson. 1988. A low cost microcomputer-based image analysis system for the measurement of percent ground cover. Res. Dev. Agric. 5:65-70.

Stutte, G. W. 1990. Analysis of video images using an interactive image capture and analysis system. HortScience 25:695-697,

Thomas, D. L., F. J. da Silva, and W A. Cromer. 1988. Image processing techniques for plant canopy cover evaluation. Trans. ASAE 31:428-434.

Page 10 of 10 